\title{
Managing Pemphigoid Gestationis
}

\author{
Authors: \\ Christine Sävervall, ${ }^{*}$ Simon Francis Thomsen ${ }^{1,2}$ \\ 1. Department of Dermatology, Bispebjerg Hospital, Copenhagen, Denmark \\ 2. Department of Biomedical Sciences, University of Copenhagen, Copenhagen, \\ Denmark \\ *Correspondence to simonfrancisthomsen@gmail.com \\ Disclosure: $\quad$ The authors have declared no conflicts of interest. \\ Received: $\quad 05.01 .20$ \\ Accepted: $\quad 20.02 .20$ \\ Keywords: $\quad$ Pemphigoid gestationis (PG), pregnancy, treatment. \\ Citation: $\quad$ EMJ. 2020;5[2]:125-135
}

\section{Abstract}

Pemphigoid gestationis (PG) is important to diagnose and treat because it carries considerable morbidity for the pregnant woman and can also constitute a risk to the fetus. Herein, the treatment options for PG and a proposed treatment algorithm for PG during pregnancy, breastfeeding, and late postpartum are reviewed.

\section{INTRODUCTION}

Pemphigoid gestationis (PG) is a rare pruritic autoimmune blistering skin disease associated with pregnancy and is classified as a pregnancyspecific dermatosis.

The estimated incidence of PG is approximately 1 in 60,000 pregnancies, and shows a worldwide distribution. ${ }^{1-3}$ The eruption commonly presents in the second or third trimester but can also occur during first trimester or the immediate postpartum period. ${ }^{3-6} \mathrm{PG}$ affects both primiparous and multiparous women, and recurrences in subsequent pregnancies are common. ${ }^{2,7}$

The pathogenesis of PG is still largely elusive but it belongs to the group of autoimmune blistering skin disorders featuring an auto-reactive immune response directed against different hemidesmosomal proteins, BP180 and BP230, affecting the adherence between the dermis and epidermis, causing blistering of the skin and mucosal membranes. ${ }^{8}$

The diagnosis of PG is based upon a combination of a profound clinical evaluation, histological findings, direct immunofluorescence, indirect immunofluorescence, and measurements of serum levels of anti-BP180 antibodies using ELISA.

PG initially presents with intense pruritus, which can occasionally remain the only symptom, but in most cases pruritus precedes the onset of inflammatory, polymorphic skin lesions. The lesions usually start as urticarial papules and annular plaques, followed by vesicles and finally large, tense, bullae on an erythematous background (Figure 1), ${ }^{1,5,7}$ Lesions typically develop on the abdomen and the most common and characteristic eruption site is the periumbilical area. ${ }^{1,3,4,6}$ In most cases it spreads to the rest of the abdomen and in some patients even thighs, palms, and soles of the feet are involved. 3,5,7,9 Lesions are rarely seen on the face or mucous membranes. ${ }^{3,5}$ 

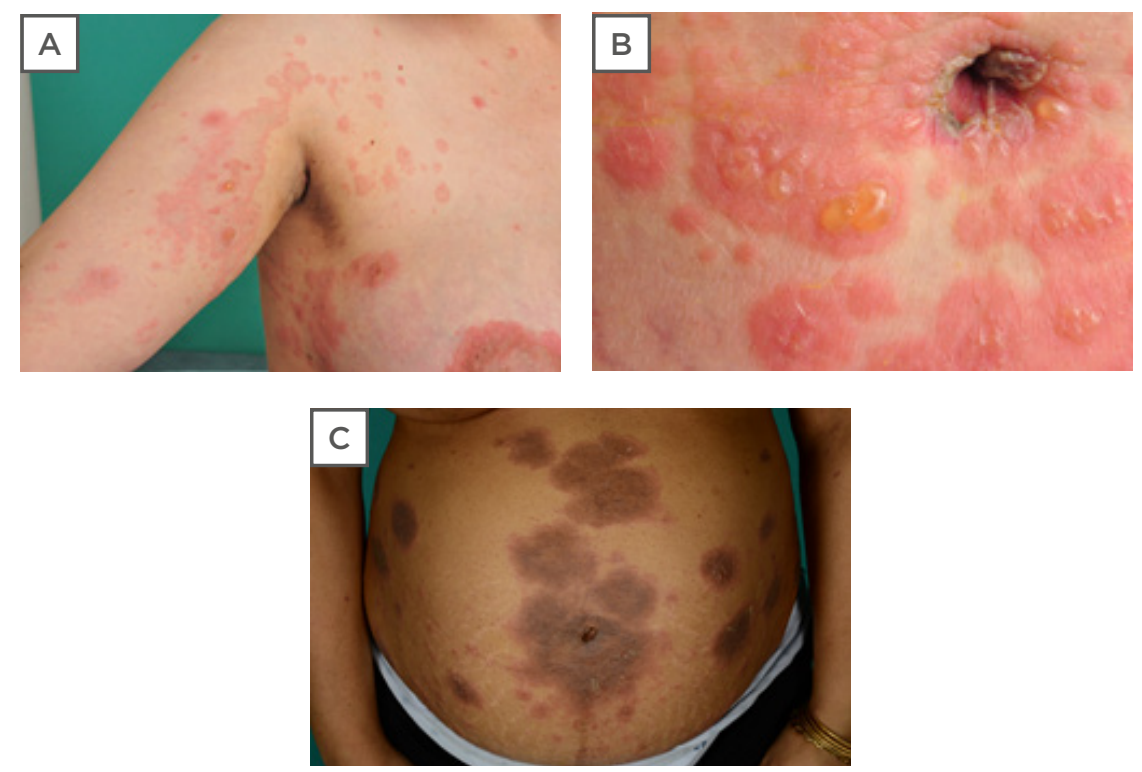

Figure 1: Clinical features of pemphigoid gestationis.

A) blisters on an erythematous background; B) periumbilical affection; C) abdominal eruption.

Most patients experience a spontaneous remission within weeks to months after delivery, even without treatment, but a peripartum flare and continued symptoms in the postpartum period have been reported..$^{10,11}$ PG often returns in subsequent pregnancies. In rare cases, PG becomes chronic or nonresponsive to treatment and is then difficult to distinguish from bullous pemphigoid. ${ }^{4,12}$

Herein, different treatments for PG and a suggested algorithm for treatment based on available data are discussed and evaluated. The PubMed database was searched for available original studies and case reports or case series describing a treatment for $P G$, and included additional references from scrutinised reference lists. As a result of the search not being organised as a complete systematic review search, some minor reports without additional relevant information were omitted.

\section{TREATMENT}

There are many case reports on treatments for PG but only a few larger studies, and the therapies for PG have not been evaluated in randomised controlled trials. The main goals of treatment are to relieve pruritus, to prevent blister formation, and to promote the healing of blisters and erosions. In general, the regimen and duration should be dictated by symptom severity and clinical response. In mild cases, oral antihistamines and moderate-to-potent topical corticosteroids can be sufficient, but in more severe cases oral corticosteroids are the drug of choice. Third-line treatments are generally reserved for refractory cases. Severe, persistent postpartum PG may require higher doses of systemic corticosteroids or other immunosuppressant agents. Dressings and topical antibacterial agents should be applied to eroded areas to prevent secondary infection. Table 1 shows an overview of available treatments and possible side effects. A suggested algorithm for treatment is presented in Figure 2. In a study in the UK, 13 (18.8\%) out of 69 patients were treated with topical corticosteroids as sole therapy, whereas 56 (81.2\%) required systemic corticosteroids with initial doses of prednisolone ranging $5-110 \mathrm{mg} /$ day. Topical corticosteroids were deemed inadequate once blisters had developed. Most patients underwent remission with systemic corticosteroids but 15 (21.7\%) required additional treatment with other systemic immunosuppressants. Only two patients were completely refractory to treatment and eruptions persisted for more than 10 years. ${ }^{4}$ In a study from Saudi Arabia of 32 patients, 75\% responded to systemic corticosteroids, whereas one patient needed intravenous Ig (IVIG). 
Table 1: Treatment recommendations for pemphigoid gestationis.

\begin{tabular}{|c|c|c|c|c|c|}
\hline & \multicolumn{3}{|c|}{ Usage } & \multirow{2}{*}{$\begin{array}{c}\text { Maternal side } \\
\text { effects }\end{array}$} & \multirow[t]{2}{*}{ Fetal risks } \\
\hline & Pregnancy & Breastfeeding & Late postpartum & & \\
\hline \multicolumn{6}{|l|}{ First-line therapy } \\
\hline $\begin{array}{l}\text { Topical } \\
\text { corticosteroids }\end{array}$ & Safe & $\begin{array}{l}\text { Safe } \\
\text { Avoid application } \\
\text { to nipple area a } \\
\text { few hours before } \\
\text { breastfeeding. }\end{array}$ & Safe & $\begin{array}{l}\text { Itching, burning, } \\
\text { redness, bruising, } \\
\text { and skin atrophy. }\end{array}$ & $\begin{array}{l}\text { Mild: none } \\
\text { Potent: low birth } \\
\text { weight, fetal growth } \\
\text { retardation }\end{array}$ \\
\hline $\begin{array}{l}\text { Systemic } \\
\text { corticosteroids }\end{array}$ & $\begin{array}{l}\text { Safe } \\
\text { (dose- } \\
\text { dependent) }\end{array}$ & Safe & $\begin{array}{l}\text { Safe } \\
\text { (dose- } \\
\text { dependent) }\end{array}$ & $\begin{array}{l}\text { Long-term } \\
\text { effects: Cushing's } \\
\text { syndrome, } \\
\text { osteoporosis, poor } \\
\text { wound healing, } \\
\text { striae formation, } \\
\text { increased tendency } \\
\text { to acquire puerperal } \\
\text { and postoperative } \\
\text { infections. } \\
\text { Exacerbation of } \\
\text { pregnancy-specific } \\
\text { morbidities: } \\
\text { hypertension, } \\
\text { gestational } \\
\text { diabetes, and } \\
\text { pre-eclampsia/ } \\
\text { eclampsia. }\end{array}$ & $\begin{array}{l}\text { Intrauterine growth } \\
\text { retardation, } \\
\text { premature rupture } \\
\text { of membranes, } \\
\text { preterm delivery, } \\
\text { and possibly } \\
\text { increased risk of } \\
\text { orofacial clefts. }\end{array}$ \\
\hline \multicolumn{6}{|l|}{ Second-line therapy } \\
\hline Intravenous Ig & Safe & Safe & Safe & $\begin{array}{l}\text { Headache, fatigue, } \\
\text { flushing, and } \\
\text { hypotension. }\end{array}$ & None \\
\hline Apheresis & $\begin{array}{l}\text { Safe but used } \\
\text { with caution } \\
\text { because of risk of } \\
\text { fetal effects. }\end{array}$ & Safe & Safe & None & $\begin{array}{l}\text { None, but the } \\
\text { deleterious effects } \\
\text { on the placental } \\
\text { microcirculation and } \\
\text { haemodynamics } \\
\text { that can } \\
\text { subsequently } \\
\text { affect fetal growth } \\
\text { should be taken into } \\
\text { consideration. }\end{array}$ \\
\hline Immunoadsorption & Safe & Safe & Safe & None & None \\
\hline \multicolumn{6}{|l|}{ Third-line therapy } \\
\hline Rituximab & $\begin{array}{l}\text { Recommended } \\
\text { to be avoided } \\
\text { because of } \\
\text { insufficient data. }\end{array}$ & $\begin{array}{l}\text { Can be } \\
\text { used during } \\
\text { breastfeeding but } \\
\text { with caution. }\end{array}$ & $\begin{array}{l}\text { Limited data } \\
\text { but no reported } \\
\text { adverse } \\
\text { outcomes. }\end{array}$ & $\begin{array}{l}\text { Headache, fever, } \\
\text { chills, stomach pain, } \\
\text { nausea, diarrhoea, } \\
\text { heartburn, and } \\
\text { flushing. }\end{array}$ & $\begin{array}{l}\text { No reported side } \\
\text { effects }\end{array}$ \\
\hline Cyclosporine & $\begin{array}{l}\text { Considered } \\
\text { safe but should } \\
\text { be carefully } \\
\text { monitored as } \\
\text { data on pregnant } \\
\text { women are } \\
\text { sparse. }\end{array}$ & $\begin{array}{l}\text { Not } \\
\text { recommended }\end{array}$ & Safe & $\begin{array}{l}\text { Pre-eclampsia, } \\
\text { gestational } \\
\text { hypertension, } \\
\text { gestational } \\
\text { diabetes, renal } \\
\text { insufficiency, } \\
\text { bone marrow } \\
\text { suppression, } \\
\text { increased hair } \\
\text { growth, headache, } \\
\text { and cancer. }\end{array}$ & $\begin{array}{l}\text { Preterm delivery, } \\
\text { small for gestational } \\
\text { age. }\end{array}$ \\
\hline
\end{tabular}


Table 1 continued.

\begin{tabular}{|c|c|c|c|c|c|}
\hline & \multicolumn{3}{|c|}{ Usage } & \multirow{2}{*}{$\begin{array}{l}\text { Maternal side } \\
\text { effects }\end{array}$} & \multirow[t]{2}{*}{ Fetal risks } \\
\hline & Pregnancy & Breastfeeding & Late postpartum & & \\
\hline Cyclophosphamide & $\begin{array}{l}\text { Should be } \\
\text { discontinued } \\
\text { prior to } \\
\text { conception and } \\
\text { avoided during } \\
\text { pregnancy. }\end{array}$ & $\begin{array}{l}\text { Unsafe due to } \\
\text { adverse effects } \\
\text { on the infant. }\end{array}$ & Safe & $\begin{array}{l}\text { Nausea or } \\
\text { vomiting, loss of } \\
\text { appetite, stomach } \\
\text { pain, diarrhoea, } \\
\text { temporary hair } \\
\text { loss, poor wound } \\
\text { healing, missed } \\
\text { menstrual periods, } \\
\text { and changes in skin } \\
\text { colour. }\end{array}$ & $\begin{array}{l}\text { Growth retardation, } \\
\text { developmental } \\
\text { delay, craniofacial } \\
\text { defects and limb } \\
\text { abnormalities, } \\
\text { among others. }\end{array}$ \\
\hline Dapsone & $\begin{array}{l}\text { Should not be } \\
\text { used because of } \\
\text { insufficient data. }\end{array}$ & $\begin{array}{l}\text { Can be used but } \\
\text { jaundice in the } \\
\text { infant should be } \\
\text { monitored. }\end{array}$ & $\begin{array}{l}\text { Safe but should } \\
\text { be avoided } \\
\text { in patients } \\
\text { with glucose- } \\
6 \text {-phosphate } \\
\text { dehydrogenase } \\
\text { deficiency. }\end{array}$ & $\begin{array}{l}\text { Haemolysis and } \\
\text { liver inflammation. } \\
\text { In patients } \\
\text { with glucose- } \\
\text { 6-phosphate } \\
\text { dehydrogenase } \\
\text { deficiency: } \\
\text { haemolytic } \\
\text { anaemia. } \\
\end{array}$ & $\begin{array}{l}\text { Neonatal jaundice } \\
\text { Neonatal haemolysis }\end{array}$ \\
\hline Methotrexate & $\begin{array}{l}\text { Should be } \\
\text { avoided }\end{array}$ & Unsafe & $\begin{array}{l}\text { Can be used } \\
\text { Recommended to } \\
\text { be discontinued } \\
\text { at least } 3 \\
\text { months prior to } \\
\text { pregnancy. }\end{array}$ & $\begin{array}{l}\text { Liver impairment, } \\
\text { nausea, and } \\
\text { vomiting, stomach } \\
\text { pain, diarrhoea, } \\
\text { hair loss, tiredness, } \\
\text { dizziness, chills, and } \\
\text { headache. }\end{array}$ & $\begin{array}{l}\text { High teratogenic } \\
\text { risk, embryotoxicity, } \\
\text { and spontaneous } \\
\text { abortion. }\end{array}$ \\
\hline Azathioprine & $\begin{array}{l}\text { Can be used } \\
\text { but should } \\
\text { be carefully } \\
\text { monitored } \\
\text { because of a } \\
\text { small risk of birth } \\
\text { defects. }\end{array}$ & $\begin{array}{l}\text { Safe at least } 4 \\
\text { hours prior to } \\
\text { breastfeeding. }\end{array}$ & Safe & $\begin{array}{l}\text { Bone marrow } \\
\text { suppression, liver } \\
\text { impairment, and } \\
\text { hypersensitivity } \\
\text { reactions. }\end{array}$ & $\begin{array}{l}\text { Preterm and low- } \\
\text { birth weight infants } \\
\text { but sporadic } \\
\text { anomalies and } \\
\text { haematologic } \\
\text { toxicities have also } \\
\text { been reported. }\end{array}$ \\
\hline Goserelin & $\begin{array}{l}\text { Should be } \\
\text { avoided because } \\
\text { of fetal risks }\end{array}$ & Unsafe & Safe & $\begin{array}{l}\text { Hot flashes, } \\
\text { sweating, headache, } \\
\text { dizziness, mood } \\
\text { changes, vaginal } \\
\text { dryness/itching/ } \\
\text { discharge, and } \\
\text { increased or } \\
\text { decreased interest } \\
\text { in sex. }\end{array}$ & $\begin{array}{l}\text { Fetal abnormalities. } \\
\text { Animal data show } \\
\text { increase in umbilical } \\
\text { hernia in offspring } \\
\text { and decreased fetal } \\
\text { survival. }\end{array}$ \\
\hline Ritodrine & $\begin{array}{l}\text { Can be used, but } \\
\text { there is limited } \\
\text { data }\end{array}$ & No available data & No available data & $\begin{array}{l}\text { Tachycardia, } \\
\text { palpitations, tremor, } \\
\text { chest discomfort, } \\
\text { and dyspnoea, and } \\
\text { hyperglycaemia. }\end{array}$ & $\begin{array}{l}\text { Fetal tachycardia, } \\
\text { neonatal } \\
\text { hypoglycaemia, } \\
\text { hypocalcaemia, } \\
\text { and ileus. }\end{array}$ \\
\hline $\begin{array}{l}\text { Doxycycline/ } \\
\text { minocycline and } \\
\text { nicotinamide }\end{array}$ & Not safe & Not safe & Safe & Hepatotoxicity & $\begin{array}{l}\text { Teratogenicity, } \\
\text { tooth discoloration, } \\
\text { and bone growth } \\
\text { disruption. }\end{array}$ \\
\hline \multicolumn{6}{|l|}{ Adjuvant therapy } \\
\hline Oral antihistamines & Safe & Safe & Safe & $\begin{array}{l}\text { Drowsiness or } \\
\text { sleepiness, } \\
\text { dizziness, and } \\
\text { dry mouth. }\end{array}$ & None \\
\hline
\end{tabular}




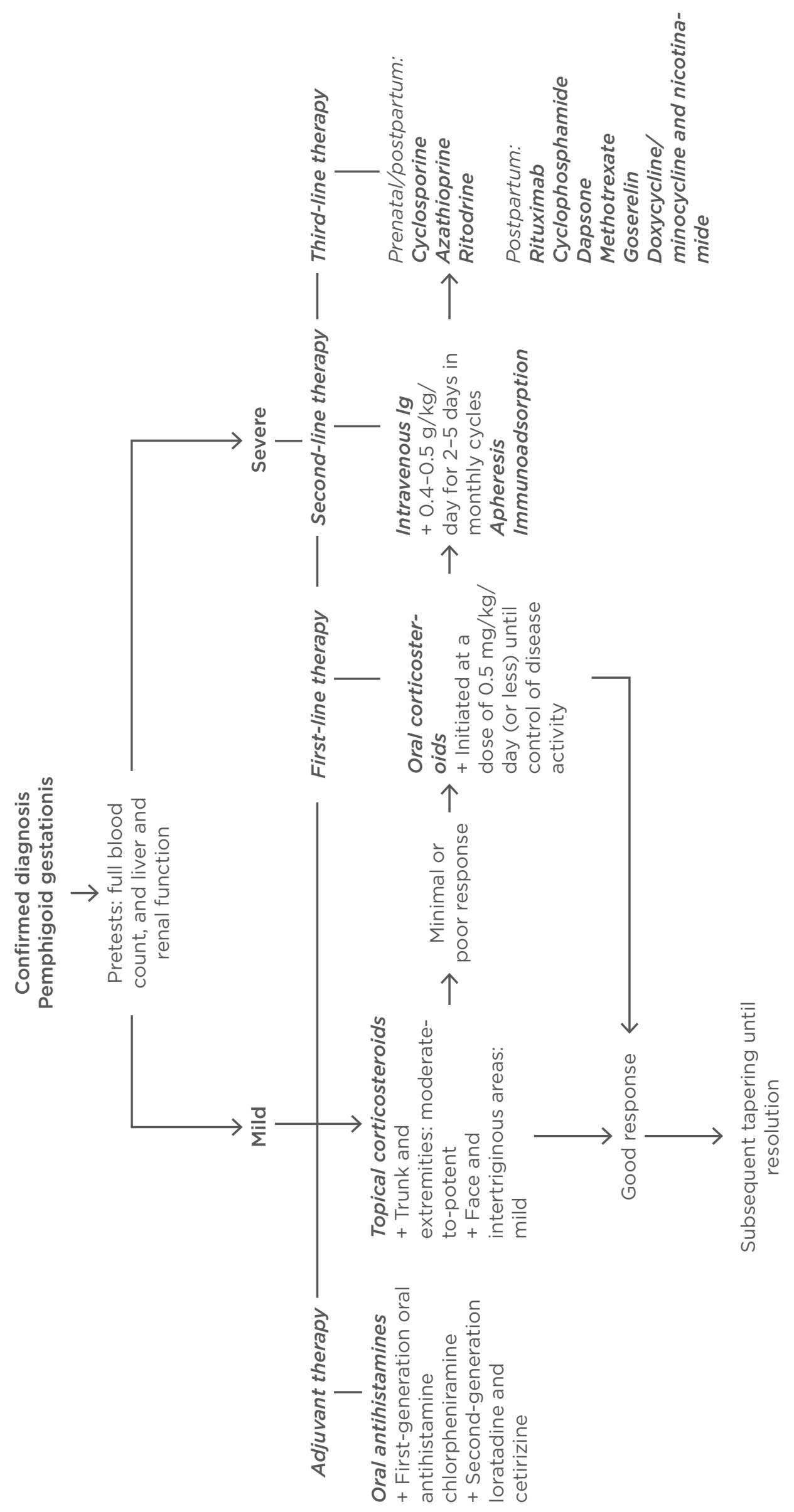

Figure 1: Treatment algorithm for pemphigoid gestationis. 
Most patients (61\%) were free of symptoms within 1-2 months of treatment. ${ }^{3}$ In a study from the UK of 15 patients, eight women were treated with systemic corticosteroids at starting doses of prednisolone ranging $30-40 \mathrm{mg} /$ day. The remainder of the women were treated with potent topical corticosteroids. Two patients required additional immunosuppressant therapy for recalcitrant disease. ${ }^{6}$

\section{First-Line Therapy}

\section{Topical Corticosteroids}

In cases of mild and localised pre-blistering PG, moderate-to-potent topical corticosteroids, with or without supplementary oral antihistamines, are adequate and first-line therapy for the trunk and extremities. If the face and intertriginous areas are involved, mild topical steroids are recommended. ${ }^{4-7} \mathrm{~A}$ systematic review on the safety of topical corticosteroids in pregnant women did not find any significant associations with congenital abnormality, such as orofacial clefts or malformation, preterm delivery, or stillbirth, but concluded that there does appear to be an association of very potent topical corticosteroids with low birth weight.

\section{Systemic Corticosteroids}

Oral corticosteroids remain the mainstay of treatment in severe cases of PG. Therapy with oral glucocorticoids is initiated at a dose of 0.5 $\mathrm{mg} / \mathrm{kg} /$ day (or less) until control of disease activity is achieved, with subsequent tapering until resolution. The maintenance dose depends on the severity of the disease and minimum effective doses should be used to reduce the risk of side effects to both mother and fetus. In the case of a flare postpartum, the dose should be increased correspondingly. The mother may experience side effects that occur because of long-term use of corticosteroids, such as Cushing's syndrome, osteoporosis, poor wound healing, striae formation, increased tendency to acquire puerperal and postoperative infections, and exacerbation of pregnancy-specific morbidities such as hypertension, gestational diabetes, pre-eclampsia, and eclampsia. ${ }^{13,14}$ A case report of a patient with PG reported that gestational diabetes can occur after a week of high-dose prednisolone. ${ }^{15}$
Aside from the effects on the mother, use of systemic corticosteroids can also cause potential risks to the fetus. Studies on autoimmune blistering disorders and the use of systemic corticosteroids have shown that prenatal exposure to prednisone may result in intrauterine growth retardation, premature rupture of membranes, or preterm delivery. ${ }^{14}$ An increased risk of orofacial clefts has been reported in smaller studies, but has been incongruent with the results in larger studies. ${ }^{16,17}$ A study of 39 women with PG compared to 22 normal controls showed that systemic corticosteroid treatment does not substantially affect pregnancy outcomes, justifying its use for pregnant women with PG.18

Prednisone transmission in breast milk is less than $0.1 \%$ of the dose ingested by the mother, which is usually less than $10.0 \%$ of the infant's endogenous cortisol production. ${ }^{19}$ These smallto-moderate amounts of corticosteroids do not appear to have adverse effects on the developing infant; however, nursing 3-4 hours after a dose is recommended because a peak in concentration occurs 2 hours after intake. 20,21

\section{Second-Line Therapy}

\section{Intravenous Immunoglobulin}

IVIG is often added to an existing regimen of corticosteroids and other immunosuppressants. It is used in severe, refractory cases and especially if risk factors such as poorly controlled diabetes and immunosuppression coexist. The recommended doses range from 0.4 to $0.5 \mathrm{~g} / \mathrm{kg} /$ day for 2-5 days in monthly cycles. In a study of 61 patients with pemphigus vulgaris who did not respond to prednisolone, IVIG was an effective and safe treatment.22 Several case reports have reported successful treatment with IVIG on patients with $P G$ during pregnancy and the postpartum period; therefore, IVIG is considered a safe treatment option during pregnancy. ${ }^{10,12,23-25}$ A case report of a woman with PG and gestational diabetes reported that the patient was successfully treated with IVIG, and symptoms improved within 4 weeks of therapy. ${ }^{10}$ IVIG has also been used successfully as a steroid-sparing agent in antepartum PG. ${ }^{26}$ The most common side effects are headaches, fatigue, flushing, and hypotension. ${ }^{27}$ 


\section{Apheresis}

Plasmapheresis during pregnancy is often used in combination with IVIG or immunosuppressants such as glucocorticoids. Case reports of two pregnant women with severe PG unresponsive to conventional treatment reported treatment with plasmapheresis to be successful and safe during pregnancy. In both cases, a specific immune apheresis was used in conjunction with systemic corticosteroids. The immune apheresis induced a rapid improvement and almost complete clearance of clinical symptoms without notable side effects in both cases. ${ }^{28,29}$ In another case report of a 40-year-old woman, for which treatment with antihistamines and pyridoxine was ineffective, plasmapheresis was carried out with rapid resolution of skin lesions and pruritus. Systemic corticosteroids were not used due to hypertension. No side effects were reported. ${ }^{30}$ A case with unsuccessful treatment has also been reported: a 38-year-old woman with PG persistent for 26 months received plasmapheresis in five trials in conjunction with high doses of oral prednisolone, azathioprine, and dapsone without sufficient response. ${ }^{31}$ No adverse side effects were reported but the deleterious effects of plasmapheresis on the placental microcirculation and haemodynamics that can subsequently affect fetal growth should be taken into consideration when used during pregnancy. ${ }^{32}$

\section{Immunoadsorption}

Systemic immunoadsorption is a bloodpurification technique that enables the selective removal of $\mathrm{Ig}$ from separated plasma through high-affinity adsorbers. There are limited reports on patients with $P G$ and immunoadsorption. A 40-year-old pregnant woman with PG with inadequate response to systemic glucocorticoids received complementary immunoadsorption and 8 weeks after initiation all lesions had healed; there were no reported side effects. ${ }^{33}$

\section{Third-Line Therapy}

\section{Rituximab}

Rituximab is a chimeric monoclonal antibody directed against the CD2O receptor located on pre-B, naïve, and memory B lymphocytes. There are limited data on the use of rituximab and patients with PG. In a case report, a 31-year-old woman diagnosed with PG experienced a severe flare postpartum. Treatment with prednisone and azathioprine was unsuccessful, and despite additional dapsone and IVIG, the response was only partial and with temporary improvement. She received rituximab at $375 \mathrm{mg} / \mathrm{m}^{2}$ and remission was complete after 6 months of treatment. No side effects were noted..$^{34}$ In another case report, a 36-year-old woman diagnosed with $P G$ in her third pregnancy received preventive treatment with rituximab in her fifth pregnancy. Treatment was successful and there was no recurrence of symptoms. It is recommended to avoid rituximab during pregnancy because of insufficient data, but this case report showed no signs of side effects in the mother or fetus. ${ }^{35}$

\section{Cyclosporine}

Cyclosporine is a potent immunosuppressant that works through calcineurin inhibition. It crosses the placenta in high quantities, but is rapidly cleared from the newborn and has not been shown to be teratogenic, mutagenic, or myelotoxic in animal models, except when used in very high doses. ${ }^{36}$ Cyclosporine therapy during pregnancy is considered non-toxic and may be a safe alternative for patients with autoimmune disease refractory to conventional treatment; however, use should be carefully monitored because data on pregnant women are sparse. ${ }^{37}$ Available data on the safety in pregnant women are mostly from transplant recipients and in those studies cyclosporine did not appear to increase the rate of malformation frequency or low birth weight. ${ }^{38,39}$ A review of available data reports that it may be associated with increased rates of prematurity. ${ }^{39}$

Efficacy in treating PG has been demonstrated and reported in all published cases. Cyclosporine has been used in conjunction with other immunosuppressants. In a case report of a 17-year-old with severe persistent PG, cyclosporine was used in combination with prednisolone and IVIG treatment. She was diagnosed with $P G$ in Week 20 and experienced in utero fetal death at 30 weeks of gestation. Symptoms were persistent postpartum and treatment with cyclosporine was started 7 months postpartum. Despite treatment, blistering continued up to 1.5 years and was thought to have an overlap with bullous pemphigoid due to cyclical, persistent 
blistering without hormonal treatment. ${ }^{12}$ In a case report of a 26-year-old woman with severe PG postpartum, unsuccessfully treated with systemic corticosteroids and azathioprine, the patient experienced remission within 1 week when therapy was changed to a combination of IVIG and cyclosporine. ${ }^{23}$ Another case report on a 26-year-old woman diagnosed with PG in Week 26 achieved disease control after treatment with prednisolone in combination with oral cyclosporine in Week 30. Fetal growth restriction was detected prenatally, but no other abnormalities were detected in the newborn. ${ }^{40}$ Three patients with PG were treated with cyclosporine in combination with prednisolone: initiated antenatally in two of the patients, both diagnosed with PG in Week 27, and postpartum in one patient diagnosed in Week 31. Cyclosporine was well-tolerated and remission was achieved within 2-5 weeks. The patients who were treated antenatally experienced spontaneous preterm deliveries at 35-36 weeks, and two neonates were growth-restricted, one who received cyclosporine antenatally. ${ }^{41}$

Other side effects to be considered are preeclampsia, gestational hypertension, and gestational diabetes. ${ }^{37}$ It can also be associated with renal insufficiency, bone marrow suppression, increased hair growth, headache, and cancer.

\section{Cyclophosphamide}

Cyclophosphamide is an immunosuppressant with a broad usage. There is one case report on cyclophosphamide used in addition to oral prednisone in a patient with persistent $P G$ in the postpartum period. The patient also had antiphospholipid antibody syndrome. She was diagnosed during pregnancy and started on oral prednisone with insufficient results. Blistering continued after delivery and azathioprine was added to the treatment regimen 8 months postpartum. Azathioprine was discontinued after 4 weeks as a result of elevated liver enzymes; she was instead started on cyclophosphamide. She experienced complete remission with no reported side effects 18 months postpartum. ${ }^{42}$ There are several reports on adverse side effects of cyclophosphamide when used during pregnancy, and conclude that it should be discontinued prior to conception and avoided during pregnancy. Adverse effects include growth retardation, developmental delay, craniofacial defects and limb abnormalities, among others. ${ }^{43}$

\section{Dapsone}

Dapsone can be used for its anti-inflammatory effect. It is used as an adjuvant to corticosteroids in patients with severe, persistent PG with various results. 4,9,31,34 Dapsone should not be used during pregnancy because of insufficient data on side effects in pregnant women. Severe side effects of oral dapsone include haemolysis and liver inflammation. A review on pregnant women with malaria treated with dapsone reported no adverse maternal or fetal outcomes. Two congenital abnormalities were reported but no causal link could be established. ${ }^{44}$ In patients with glucose-6-phosphate dehydrogenase deficiency, dapsone should be avoided because of the risk of developing haemolytic anaemia. A blood sample testing for glucose-6phosphate dehydrogenase deficiency should be ordered before initiating treatment. ${ }^{45}$ Neonatal jaundice has also been reported with the use of dapsone during pregnancy and is suggested to be monitored along with controls for neonatal haemolysis. ${ }^{46}$

\section{Methotrexate}

Methotrexate is effective for controlling disease activity in autoimmune bullous disordes. ${ }^{47}$ Methotrexate is contraindicated during pregnancy because of a high teratogenic risk, embryotoxicity, and spontaneous abortion, and should be avoided during pregnancy. ${ }^{48}$ Treatment with methotrexate is recommended to be discontinued at least 3 months prior to pregnancy in both men and women. ${ }^{14}$ Breastfeeding is also contraindicated because it transfers into breastmilk. ${ }^{20}$ Methotrexate was reported not to be useful in a patient with severe PG, in whom symptoms persisted for 11 years postpartum. ${ }^{49}$

\section{Azathioprine}

Azathioprine is a synthetic purine-based analogue. ${ }^{14}$ It has been used as an adjunct to systemic corticosteroids in cases with severe, persistent $P G$ in the postpartum period, with various results. ${ }^{24,26,31,34,50}$ In a case report of a 35-year old woman with $P G$ in both her pregnancies who failed to respond to high-dose systemic prednisolone, the patient was treated successfully with IVIG followed by treatment with azathioprine to adequately control her symptoms postpartum. Six months postpartum, she experienced a flare despite oral corticosteroids, 
and she was started with azathioprine at a dose of $1 \mathrm{mg} / \mathrm{kg} /$ day. Her disease activity remained stable and treatment continued for another 8 months. It was not possible to tell whether it was a result of a spontaneous resolution of the disease or the treatments given. No side effects were reported. ${ }^{26}$ In two other cases treatment was ineffective or with only partial response..$^{24,34}$

Azathioprine may cause bone marrow suppression, liver impairment, and hypersensitivity reactions. Pregnant women should be carefully monitored if treated with azathioprine because of a small risk of birth defects. The main risks are preterm and low-birth-weight infants, but sporadic anomalies and haematologic toxicities have also been reported. ${ }^{14} \mathrm{~A}$ study of 476 women taking azathioprine during early pregnancy for a variety of indications supports the increased risk of preterm and low-birth-weight infants without a statistically significant increase in rates or patterns of congenital malformations. ${ }^{51}$ No adverse events have been reported in breastfed infants who are exposed to maternal azathioprine. ${ }^{20}$

\section{Goserelin}

Goserelin is a luteinising hormone-releasing hormone analogue. In a case report of a 46-yearold woman diagnosed with severe PG, who had continuous symptoms despite 10 years of treatment with high dose corticosteroids, a complete remission within 6 months after initiating treatment with goserelin was experienced. ${ }^{22}$ Treatment with goserelin is considered unsafe during pregnancy because there are studies on both human and animals reporting fetal risks. ${ }^{53}$

\section{Ritodrine}

Ritodrine is a sympathomimetic drug that works as a $\beta$-agonist. In a case report of a woman diagnosed with severe PG resistant to systemic corticosteroid, the patient experienced complete and rapid remission of all symptoms when treatment with IV ritodrine initiated during pregnancy. Oral ritodrine then permitted withdrawal of corticosteroids with the pregnancy then proceeding normally until delivery. ${ }^{54}$

\section{Doxycycline/Minocycline and Nicotinamide}

Doxycycline and nicotinamide are often paired due to a synergistic anti-inflammatory and antiapoptotic effect and is suggested to be useful as a steroid-sparing therapy for patients with pemphigus. ${ }^{55}$ It is safer and with fewer side effects compared with corticosteroids and can be useful in patients with PG whose concurrent medical conditions preclude the use of systemic steroids. ${ }^{56}$

A case report on two patients with persistent PG reported successful treatment with doxycycline and nicotinamide. The first patient was a 38-yearold woman who experienced a postpartum flare lasting for 2 years. She tried several different treatment strategies, including systemic corticosteroids, azathioprine, dapsone, and plasmapheresis, all with only partial improvement. She developed hypertension and a Cushingoid habitus, and treatment with doxycycline and nicotinamide in parallel with a tapering of corticosteroid was initiated. The bullous lesions disappeared within 4 weeks of treatment. The second patient had persistent lesions postpartum and had only partial effect of topical steroids. She was successfully treated with doxycycline and nicotinamide after she finished breastfeeding and complete remission was obtained within 2 months. ${ }^{56}$ Another case of a 24-year-old woman with PG with persisting symptoms 12 months postpartum, was treated successfully with a combination of minocycline and nicotinamide in combination with a lower dose of prednisolone, has been reported. She was diagnosed with PG in her first pregnancy but developed Cushingoid habitus with high doses of systemic steroids. The alternative regimen was therefore tested with good results, and she had no further blisters 3 months after treatment was initiated..$^{57}$

Tetracyclines have an increased risk for teratogenicity, tooth discolouration, bone growth disruption, and maternal hepatotoxicity, and should not be administrated during pregnancy or while breastfeeding. The teratogenic effect of doxycycline has not been documented but data is limited and should be avoided. ${ }^{58}$ 


\section{Adjuvant Therapy}

\section{Antihistamines}

Oral antihistamines are used to relieve pruritus. They are usually used in combination with topical or systemic steroids to keep the symptoms and the disease in control. First-generation oral antihistamine chlorpheniramine or secondgeneration loratadine and cetirizine are suitable choices. In a meta-analysis examining the safety of first-generation antihistamines in pregnancy, 200,000 first trimester exposures failed to show increased teratogenic risk. ${ }^{59}$ Second-generation antihistamines are not as well-studied in pregnant women; however, in a cohort study and meta-analysis, cetirizine was not associated with an increased risk of major malformations or other adverse fetal outcomes. ${ }^{60}$ It is considered safe to use during breastfeeding. ${ }^{21}$

\section{Other Treatments}

In addition to medication, there are other suggested, potentially helpful methods to reduce pruritus such as emollients containing menthol or pramoxine, and oatmeal baths. ${ }^{6}$ Ultraviolet light therapy is relatively contraindicated because it may promote new blister formation. Dressings and topical antibacterial agents should be applied to eroded areas to prevent secondary infection. Intact large blisters may be drained with a sterile, large-bore needle, but care must be taken to avoid unroofing blisters. ${ }^{53}$

\section{CONCLUSION}

Treatment of PG is important to decrease adverse pregnancy and fetal outcomes. Systemic glucocorticoids, with or without oral antihistamines, remain the first line of therapy for $P G$ and are relatively safe during pregnancy and the postpartum period. In unresponsive cases, patients may benefit from systemic immunoadsorption, apheresis, and IVIG. In cases of persisting (postnatal) symptoms, systemic immunosuppressants such as cyclosporine, cyclophosphamide, dapsone, azathioprine, rituximab, or methotrexate might be beneficial. Other alternatives, for which there are limited data but have had successful results, are doxycycline/minocycline, nicotinamide, ritodrine, and goserelin.

No drug is safe beyond all doubt in pregnancy and any systemic treatment should be prescribed with caution and at lowest possible dose for the shortest possible exposure period.

\section{References}

1. Ambros-Rudolph CM et al. The specific dermatoses of pregnancy revisited and reclassified: results of a retrospective two-center study on 505 pregnant patients. JAAD. 2006;54(3):395-404.

2. Shornick JK et al. Herpes gestationis: clinical and histologic features of twenty-eight cases. JAAD. 1983;8(2):214-24

3. Al-Saif $\mathrm{F}$ et al. Retrospective analysis of pemphigoid gestationis in 32 Saud patients - clinicopathological features and a literature review. J Reprod Immunol. 2016;116:42-5.

4. Jenkins RE et al. Clinical features and management of 87 patients with pemphigoid gestationis. Clin Exp Dermatol. 1999;24(4):255-9.

5. Mokni $\mathrm{M}$ et al. [Pemphigoid gestationis: a study of 20 cases]. Ann Dermatol Venereol. 2004;131(11):9536. (In French)

6. Vaughan Jones SA et al. A prospective study of 200 women with dermatoses of pregnancy correlating clinical findings with hormonal and immunopathological profiles. Br J Dermatol. 1999;141(1):7181.

7. Hallaji Z et al. Pemphigoid gestationis: Clinical and histologic features of twenty-three patients. Int J Womens Dermatol. 2017;3(2):86-90.

8. Schmidt E, Zillikens D. Pemphigoid diseases. Lancet (London, England). 2013;381(9863):320-32.

9. Castro LA et al. Clinical experience in pemphigoid gestationis: report of 10 cases. JAAD. 2006;55(5):823-8.

10. Nguyen $T$ et al. Positive clinical outcome with IVIg as monotherapy in recurrent pemphigoid gestationis. Int Immunopharmacol. 2015;26(1):1-3.

11. Zubor P et al. Early flare-up of severe Herpes gestationis (Pemphigoid gestationis) and successfull prolonged treatment: a case report. $J$ Obstet Gynaecol. 2017;37(6):824-6.
12. Hern $\mathrm{S}$ et al. A severe persistent case of pemphigoid gestationis treated with Intravenous immunoglobulins and cyclosporin. Clin Exp Dermatol. 1998;23(4):185-8.

13. Moghadam-Kia S, Werth VP. Prevention and treatment of systemic glucocorticoid side effects. Int J Dermatol. 2010;49(3):239-48.

14. Braunstein I, Werth V. Treatment of dermatologic connective tissue disease and autoimmune blistering disorders in pregnancy. Dermatol Ther. 2013;26(4):354-63

15. Heazell AE et al. A case of gestational diabetes arising following treatment with glucocorticosteroids for pemphigoid gestationis. J Matern Fetal Neonatal Med. 2005;18(5):3535.

16. Skuladottir $\mathrm{H}$ et al. Corticosteroid use and risk of orofacial clefts Birth Defects Res. 2014;100(6):499-506.

17. Hviid A, Molgaard-Nielsen D. Corticosteroid use during pregnancy 
and risk of orofacial clefts. CMAJ. 2011;183(7):796-804.

18. Chi $\mathrm{CC}$ et al. Pemphigoid gestationis: early onset and blister formation are associated with adverse pregnancy outcomes. Br J Dermatol. 2009;160(6):1222-8.

19. Greenberger PA et al. Pharmacokinetics of prednisolone transfer to breast milk. Clin Pharmacol Ther. 1993;53(3):324-8.

20. Elliott $A B$, Chakravarty EF. Immunosuppressive medications during pregnancy and lactation in women with autoimmune diseases. Womens health. 2010;6(3):431-40.

21. Butler DC et al. Safety of dermatologic medications in pregnancy and lactation: Part II. Lactation. JAAD. 2014;70(3):417.e1-10.

22. Amagai $M$ et al. A randomized double-blind trial of intravenous immunoglobulin for pemphigus. JAAD. 2009;60(4):595-603.

23. Hapa A et al. A resistant case of pemphigus gestationis successfully treated with intravenous immunoglobulin plus cyclosporine. Int J Dermatol. 2014;53(4):269-71.

24. Kreuter $A$ et al. Intravenous immune globulin in the treatment of persistent pemphigoid gestationis. JAAD. 2004;51(6):1027-8.

25. Yang A et al. Pemphigoid gestationis and intravenous immunoglobulin therapy. Int J Womens Dermatol. 2018;4(3):166-9.

26. Gan DC et al. Successful treatment of a severe persistent case of pemphigoid gestationis with antepartum and postpartum intravenous immunoglobulin followed by azathioprine. Australas J Dermatol. 2012;53(1):66-9.

27. Seidling $\vee$ et al. Analysis of highdose intravenous immunoglobulin therapy in 16 patients with refractory autoimmune blistering skin disease: high efficacy and no serious adverse events. Acta Derm Venereol. 2013;93(3):346-349

28. Marker M et al. Successful immunoapheresis of bullous autoimmune diseases: pemphigus vulgaris and pemphigoid gestationis. J Dtsch Dermatol Ges. 2011;9(1):27-31

29. Wohrl S et al. Pemphigoid gestationis: treatment with immunoapheresis. J Dtsch Dermatol Ges. 2003;1(2):12630.

30. Van de Wiel A et al. Plasma exchange in herpes gestationis. BMJ.1980;281(6247):1041-2.

31. Amato $L$ et al. A case of chronic herpes gestationis: persistent disease or conversion to bullous pemphigoid? JAAD. 2003;49(2):302-7.

32. Jako $\mathrm{M}$ et al. Postnatal outcome and placental blood flow after plasmapheresis during pregnancy. $J$ Matern Fetal Neonatal Med. 2017;30(22):2755-8.

33. Westermann $L$ et al. Glucocorticosteroid-resistant pemphigoid gestationis: successful treatment with adjuvant immunoadsorption. J Dermatol. 2012;39(2):168-71.

34. Cianchini G et al. Severe persistent pemphigoid gestationis: long-term remission with rituximab. BR J Dermatol. 2007;157(2):388-9.

35. Tourte $M$ et al. Pemphigoid gestationis: a successful preventive treatment by rituximab. J Eur Acad Dermatol Venereol. 2017;31(4):206-7.

36. Ryffel $B$ et al. Toxicological evaluation of cyclosporin A. Arch Toxicol. 1983;53(2):107-41.

37. Paziana K et al. Ciclosporin use during pregnancy. Drug saf. 2013;36(5):279-94

38. Armenti VT et al. National transplantation Pregnancy Registryoutcomes of 154 pregnancies in cyclosporine-treated female kidney transplant recipients. Transplant. 1994;57(4):502-6.

39. Bar Oz B et al. Pregnancy outcome after cyclosporine therapy during pregnancy: a meta-analysis. Transplant. 27 2001;71(8):1051-5.

40. Ozdemir O et al. A resistant case of pemphigus gestationis successfully treated with cyclosporine. Interv Med Appl Sci. 2016;8(1):20-2.

41. Huilaja L et al. Cyclosporine treatment in severe gestational pemphigoid. Acta Derm Venereol. 2015;95(5):593-5.

42. Castle SP et al. Chronic herpes gestationis and antiphospholipid antibody syndrome successfully treated with cyclophosphamide. JAAD. 1996;34(2):333-6.

43. Rengasamy P. Congenita Malformations Attributed to Prenatal Exposure to Cyclophosphamide. Anticancer Agents Med Chem. 2017;17(9):1211-27.

44. Nosten $\mathrm{F}$ et al. Antimalarial drugs in pregnancy: a review. Curr Drug Saf. 2006;1(1):1-15.

45. Jollow DJ et al. Dapsone-induced hemolytic anemia. Drug Met Rev. 1995;27(1-2):107-24.

46. McPherson $\mathrm{T}$, Venning $\mathrm{VV}$.
Management of autoimmune blistering diseases in pregnancy. Dermatol Clin. 2011;29(4):585-90.

47. Hooten $\mathrm{J}$ et al. Updates on the management of autoimmune blistering diseases. Skin Therapy Lett. 2014;19(5):1-6.

48. Hyoun SC et al. Teratogen update: methotrexate. Birth Defects Res. 2012;94(4):187-207.

49. Fine JD, Omura EF. Herpes gestationis. Persistent disease activity 11 years post partum. Arch Dermatol. 1985;121(7):924-6.

50. Sereno $\mathrm{C}$ et al. Refractory herpes gestationis responsive to intravenous immunoglobulin: a case report. JAAD. 2005;52(3):P116.

51. Cleary BJ, Kallen B. Early pregnancy azathioprine use and pregnancy outcomes. Birth Defects Res. 2009;85(7):647-54.

52. Garvey MP et al. Pemphigoid gestationis--response to chemical oophorectomy with goserelin. Clin Exp Dermaol. 1992;17(6):443-5.

53. Intong LR, Murrell DF. Pemphigoid gestationis: current management. Dermatol Clin. 2011;29(4):621-8.

54. Macdonald KJ, Raffle EJ. Ritodrine therapy associated with remission of pemphigoid gestationis. BR J Dermatol. 1984;111(5):630.

55. McCarty M, Fivenson D. Two decades of using the combination of tetracycline derivatives and niacinamide as steroid-sparing agents in the management of pemphigus: defining a niche for these low toxicity agents. JAAD. 2014;71(3):475-9.

56. Amato $L$ et al. Successful treatment with doxycycline and nicotinamide of two cases of persistent pemphigoid gestationis. The Journal of dermatological treatment. 2002;13(3):143-146.

57. Loo WJ et al. A severe persistent case of recurrent pemphigoid gestationis successfully treated with minocycline and nicotinamide. Clin Exp Dermatol. 2001;26(8):726-7.

58. Kushner CJ et al. Treatment of Autoimmune Bullous Disorders in Pregnancy. Am J Clin Dermatol. 2018;19(3):391-403.

59. Seto A et al. Pregnancy outcome following first trimester exposure to antihistamines: meta-analysis. Am J Perinatol. 1997;14(3):119-24.

60. Etwel F et al. The fetal safety of cetirizine: an observational cohort study and meta-analysis. J Obstet Gynaecol. 2014;34(5):392-9. 